\title{
Hoarding plastic waste: Buried alive
}

\author{
A. Rachelle Foss* \\ MacEwan University, Canada
}

\begin{abstract}
Plastic is a ubiquitous part of our everyday lives. Popular for its versatility, it can be attributed to the creation of the numerous conveniences we enjoy in contemporary society. However, traditional plastic does not break down and thus has also become ubiquitous within the environment, and the mounting consequences to its extensive use is being seen. Recycling provides a degree of relief in our efforts to address this problem and can be a boost to the economy but there are barriers that reduce the effectiveness of this solution. In addition to the complex and arduous process of separating and preparing different plastics for recycling, many plastics never reach recycling facilities. But even more common is the inability of many facilities to handle most types of plastics. Biodegradable plastics have been introduced to address this issue. However, bio-plastics also have proven failings, one of which is the damage they cause within the traditional recycling stream and concerns over increased littering. With the ever- accumulating material now reaching almost every part of the earth, governments must consider changing the laws to regulate the plastics we allow in our country before the earth is buried under the remnants our conveniences.
\end{abstract}




\section{Introduction: A Mounting Concern}

Plastic has become a ubiquitous product on the planet; it is the vehicle for many conveniences. As such, the material is so ingrained in daily life, most people are not aware of how many products are produced using it. The startling reality is many of our products would not exist without plastic. The number of single and temporary use plastic items we would find the list is exhaustive. It is used to make toothbrushes, electronics, the foam in a pair of slippers, the fridge, and it goes on (Ian Connacher, 2008, ch.1). Plastic's versatility gives it tremendous value and while this versatility is an asset it is also a flaw. The material's versatility and universal use has made it a widespread and incessant problem that litters our earth. It fills garbage dumps, spilling over to litter beaches, lakes and oceans, mountains and valleys (Moore, 2011, p. 5). This is because "every single piece of plastic made over the past 60 years is still there, in one form or another" (Ian Connacher, 2008, ch. 1). In their book, Plastic Ocean, Moore and Philips (2001) state that "plastic litter has been found in every single part of the seven seas from the floor of the Arctic Ocean to the farthest reaches of the Pacific. And it's not going away" (p. 2).

We cannot rely on recycling alone to solve this ever-increasing problem. Government legislation controlling the plastics manufacturers use to produce products sold in Canada, ensuring single and temporary use products are only made with biodegradable material, and that long term use products are made of recyclable plastic material can help. These laws can be used to address and begin to resolve issues surrounding waste pollution and recycling shortfalls.

\section{Plastic: The Virtue of Convenience and Vice of Durability}

Although "plastic in essence is a material that is mouldable when heated and retains the shape once cooled" (Alberta Plastics Recycling Association [APRA], 2013, para. 1) including naturally occurring plastic like amber (APRA, 2013, para. 1). Modern plastic is a man-made material composed of various polymers, also known as resins, derived from crude oil and natural gas. Plastic come in many varieties ranging from brittle to flexible to lightweight foam. It is used to produce most items we use daily including mixing bowls, toys, and vehicle parts.

Single use and temporary use items include plastic bags, water bottles, straws, to go containers, utensils, plastic wrap (saran), sandwich bags, toothbrushes, razors, and the list continues (Plastic Pollution Coalition, 2010, para. 1-4). Many of these single use items have become a permanent fixture in society since 1957, and the convenience they 
provide only increases their popularity (SPi The Plastic Industry Trade Association, 2012 para. 4).

There is no denying that plastic is an indispensable product, but according to research by documentary film director, Ian Connacher, (2008), "virtually no organism can degrade plastic. Which means every piece that has ever been made, except for a small amount that has been incinerated, still exists" (ch. 1).

This points to serious consequences when we consider that "Canadians take home an estimated 2.86 billion plastic bags each year" (Banks, 2008, para 1). The majority of plastic ends up in one of Canada's estimated 2,400 landfills (Landfill Inventory Management Ontario, 2011, para. 1) where it does not break down (Ian Connacher, 2008, ch. 1). The landfill's hermetic seal blocks the oxygen, moisture, and air necessary for the right organisms to breakdown our garbage and "without oxygen, air, moisture and the right organisms, nothing will breakdown or go away" (Ian Connacher, 2008, ch.1). According to Statistics Canada, there is concern that as landfills near capacity, municipalities struggle to find locations for new ones (Babooram \& Wang, 2008, para.1).

Off the pacific coast of North America a circulating set of currents, known as the North Pacific Gyre, trap a steadily increasing amount of non-degrading plastic garbage and fragments. The North Pacific Gyre has come to be nicknamed the Pacific "Garbage Patch" (Ian Connacher, 2008, ch.1).

Globally the problem is even more pervasive, and it's not just a problem that exists in developed countries. Colourful, filmy bags float through the air, swathe the natural foliage, fill the ditches, and hang from branches and clotheslines; A gaudy trash mosaic that bedecks the landscape. In Nairobi, Kenya, the locals call plastic bags the national flower. According to Nairobi businesswoman, Tahreni Bwanaali, "it is quite a big issue and quite a big concern" (Ian Connacher, 2008, ch.7). The overwhelming issue has prompted Kenya's government to take measures to reduce the number of plastic bags in the country (Ian Connacher, 2008, ch. 7).

European researcher, Dr. Jan van Franeker, claims roughly seven to eight kilograms of garbage wash up daily on each kilometre of beach in Holland (Ian Connacher, 2008, ch.5). Garbage, rejected from the plastic potage the ocean has become, ceaselessly washes ashore littering the world's beaches. According to a claim by the United Nations, there are "46,000 pieces of plastic in every square mile of ocean" (Ian Connacher, 2008, ch. 1) and tests of ocean water have found in some areas, the ratio is a ten to one ratio of plastic to plankton. It is also estimated that ten percent of ocean water contains nertles, 
the small plastic beads that make up the basic foundation for all plastic products (Ian Connacher, 2008, ch. 2). By nature, plastic attracts oily pollutants and the nertles, which resemble fish eggs - a common food for a lot of marine life - are no different. Many ocean fish consume nertles coated in toxic pollutants. Humans then consume the toxins when they eat the fish (Ian Connacher, 2008, ch. 4).

\section{Recycling: The Virtue of Repurpose and the Vice of Limitation}

With an estimated 13.4 million tonnes of garbage produced yearly by Canadians it is not surprising many are choosing to recycle in an attempt to reduce the waste that is being put into landfills as well as conserve natural resources (Babooram \& Wang, 2008, para. 3). Recycling is gaining popularity as a method of dealing with garbage, and according to Statistics Canada "households across the country sent nearly 3.6 million tonnes of materials for recycling in 2004, an increase of $65 \%$ compared to 2000 " (Babooram \& Wang, 2008, para. 3).

In an effort to reduce the amount of plastic waste in our landfills, many municipalities have recycling facilities to turn plastic and other recyclable materials into a useable substance once the plastic is gathered and put through a cleaning process (Clemente, 2008, para. 3).

The numerous resins used to make plastic each behave differently during the recycling process. The characteristics of individual polymers prevent them from being successfully recycled when mixed with other polymers. Plastic is separated at the recycling facility to ensure the quality of the product (Clemente, 2008, para. 4). Many plastic producers code the plastic with a number to symbolize the type of resin for easy sorting (APRA, 2013, para. 4) The plastics are then shredded into pellets or melted to create one mixture (Clemente, 2008, para. 4).

Using recycled plastic to produce useful new products requires less energy and fewer resources than producing new plastics for these manufactured goods (APRA, 2013, para. 2), and although it does not stop the production of new plastic, it does reduce it to a degree. In addition, recycling also supports the economy. According to Edmonton.ca (2013), over 90 percent of the material collected for recycling is sold (para. 1) to companies that produce goods ranging from vehicle parts to coffee cups, and plastic “bags can be recycled into plastic 'lumber,' planters for gardening, new plastic bags, and other products" (SPi, 2012, para. 3). 
However, regardless of the expanding market for recycled plastic, Edmonton's mega-recycling facility is an exception (APRA, 2013, para. 3, 4). Many other Canadian cities, including Edmonton's southern neighbor, Calgary, accept and recycle fewer types of plastic. In fact, "Calgarians joke that the easiest way to recycle mixed plastics is to stash them in the trunk next time you make a trip to Edmonton" ("Plastics: How to", 2008, para. 7).

Other Canadian cities have equally poor reputations for recycling. In 2008, "some recycling agencies in Montreal were found guilty of giving away their potential recycled waste to city dumps and landfills" (Clemente, 2008, para. 1) In Ontario, 55 percent of recyclable waste goes to the landfills (Campbell \& Dharmarajah, 2011, para. 7). The majority of recycling facilities across North America only process resin codes one and two, and "in Canada, less than 40 percent of those are recycled" (Ian Connacher, 2008, ch. 5).

Not only do recycling facilities fall short, but, according to Statistics Canada, limited access to convenient recycling facilities reduces the chance that Canadian's will recycle. People who live in single detached homes are more likely to have access to recycling services than those living in mobile homes or apartments (Babooram \& Wang, 2008, para. 4).

Nevertheless, plastic manufacturers continue to promote the recyclability of their product in an effort to increase sales (Ecology Centre, n.d., para. 2). The Alberta Recycling Plastics Association is closely affiliated with Canadian Plastic Industry Association (Canadian Plastics Industry Association, 2013, para. 1) because promoting plastic packages to seem more environmentally friendly leads consumers to feel comfortable buying more plastic products (Ecology Centre, n.d., para. 1, 2). But the truth is, of the "approximately 31 million tonnes of garbage Canadians generate each year, only about 30 percent of that material is recycled" (Recycling Council of British Columbia, n.d., para. 1).

\section{Plastic: The Virtue of Decomposition and the Vice of Complication}

Although so little traditional plastic is actually being recycled, there is good news. More and more plastic products are being manufactured from biodegradable plastics that "break down more easily and quickly than traditional plastics . . . because they are made from renewable resources" (Saskatchewan Waste Reduction Council [SWRC], 2013, para. 3). Biodegradable plastics are made from resources like corn and "have similar properties to conventional plastics like polyethylene and polypropylene" (SWRC, 2013, 
para. 4). These plastics are appearing increasingly in disposable products like "food trays, take-out containers and single-use dishes and many other packages" (SWRC, 2013, para. 4). Previously, "the term 'biodegradable' has been applied liberally by some manufacturers ... producers of true biodegradable plastics teamed up with the U.S. Composting Council to develop a standard for biodegradable plastics" (SWRC, 2013, para. 5). However, adversaries of bio-plastic are still concerned about the product, arguing that biodegradable plastics are inferior to traditional plastics.

There is concern "biodegradable plastics really don't break down in landfills" (SWRC, 2013, para. 7) and the landfill's hermetic seal impedes the breakdown of almost all materials (Ian Connacher, 2008, ch. 1). However, bio-plastics are being developed in inventive new ways and are derived from creative new materials, offering new solutions to the issues landfills are facing. Companies like Plantic Technologies Inc. are producing plastics that breakdown when exposed to water (Ian Connacher, 2008, ch. 14). While this kind of plastic will not entirely solve the issue of all the plastic in our landfills and bodies of water, it is a promising product to get started with. Additionally, plastic producers like Justin Barone, from the USDA, are making plastic from waste chicken feathers (Ian Connacher, 2008, ch. 14).

However, there are other concerns surrounding biodegradable plastics. The most frequently voiced concern is "if land is used to grow biodegradable plastic, will there be any left to grow food?" (Ian Connacher, 2008, ch. 14). According to Harald Kaeb, of European Bioplastics, two to three tonnes of bio-plastic can be grown in as few as 10,000 square metres of growing space (Ian Connacher, 2008, ch. 14).

In addition, there is the real possibility that the mass introduction of bio-plastics puts recycling revenues at potential risk. For a city like Toronto, "that generates over $\$ 20$ Million per year from the sale of recyclables to help offset the cost of collecting recyclables" the integrity of recyclable plastics is an important concern (Toronto.ca, 2009, para. 1).

Biodegradable plastics contaminate regular plastic recycling because the products are made of different material, so "biodegradable plastics belong in the composting stream, not the recycling stream" (SWRC, 2013, para. 8). Corrupted batches of recycled plastics can have a detrimental effect on recycling markets. Products "such as landscape edging, decking, and automotive parts" (Toronto.ca, 2013, para. 1) are made to be durable and it is necessary that they do not dissolve in the rain or breakdown within a few years. As such, manufacturers of recycled plastic products "refuse to buy any material which may contain any bio-plastics" (Toronto.ca, 2013, para. 1). 
This is where government legislation specifying the type of plastic that can be used for certain merchandises will not only push companies to be more conscientious about their products and packaging, but also reduce the risk of confusion between traditional petroleum based plastics and new bio-plastics. In addition, it will prompt municipalities to develop the necessary infrastructure to effectively deal with both biodegradable plastic and recyclable plastic.

Finally, some believe biodegradable products will encourage people to litter by giving them the impression there is little to no environmental impact, even though "a biodegradable plastic bag that's thrown into a hedge will still take years to disappear" (FuturEnergia, n.d., para. 2). However, this isn't a realistic concern for three reasons. First, although most people know they should not litter, many people still choose to anyway. Second, a great deal of litter is not actively thrown away by citizens, but enters the environment when it falls out of garbage cans, blows out of landfills, or by other accidental means. Third, as previously mentioned, innovation in the bio-plastics industry has led to the production of plastics that breakdown in shorter and shorter time periods.

\section{Conclusion: A Mounting Need for Action}

Currently the Canadian government is looking for ways to address concerns of plastic pollution, such as a document put out by Canadian parliament regarding the issue of plastic bags in the Canadian environment. Currently, “. . . various matters that are related to the environment are assigned to each of the federal and provincial levels of government. . . . Thus, jurisdiction in many instances will depend on the particular matter that is being regulated and the means by which regulations are to be implemented" (Banks, 2008, para. 1). However, "that said, there is nothing to prevent different levels of government from consulting, agreeing and cooperating on issues of shared concern, despite the constitutional allocation of jurisdiction" (Banks, 2008, para. 2).

Additionally, municipalities, which are responsible for managing garbage, are using their regulatory powers to prompt businesses to be proactive about waste reduction with documents such as the City of Toronto Act (Recycling Council of Ontario, 2010, para. 7).

With the amount of plastic continually increasing, it now touches almost every area of the planet to the deepest depths of the ocean, making it apparent that the issue of plastic pollution will not go away unless changes are made. To maintain the integrity of the environment, there is a need to alter the way people think of plastic as well as the 
way it is manufactured and recycled. In addition, regulations to change the types of plastic allowed within the country need to be instated. Without these changes, our earth will inevitably be buried under a mountain of plastic waste.

* Author: A. Rachelle Foss is in her final year of the Professional Writing and Communications program at MacEwan University. She has worked as an editor for both The Western Sentinel newspaper and NAIT. She has published articles in both the 2011 and 2012 editions of the Earth Common Journal, and was on the editorial board for the Journal last year.

\section{References}

Alberta Plastics Recycling Association (2013). Industry News / CPLA Lead's Tour of Edmonton's Mega-Recycling Facility. Retrieved from http://albertaplasticsrecycling.com/news/industry-news/

Alberta Plastics Recycling Association (2013). Links and Facts About Recycling / Modern Plastics. Retrieved from http://albertaplasticsrecycling.com/resourceseducation/links-and-facts-about-recycling/

Alberta Plastics Recycling Association (2013). Links and Facts about Recycling / PlasticsA Brief History. Retrieved from http://albertaplasticsrecycling.com/resourceseducation/links-and-facts-about-recycling/

Alberta Plastics Recycling Association. (2013). Plastics Identification Codes / Resin Identification Codes. Retrieved from http://albertaplasticsrecycling.com/resourceseducation/plastics-identification-codes/

Babooram, Avani, and Jennie Wang. (2008). Statistics Canada. Factors Affecting Household Recycling. Retrieved from http://www.statcan.gc.ca/pub/16-002x/2007001/article/10174-eng.htm

Babooram, Avani, and Jennie Wang. (2008). Statistics Canada. How Much do We Recycle?. Retrieved from http://www.statcan.gc.ca/pub/16-002-x/2007001/article/10174eng.htm

Babooram, Avani, and Jennie Wang. (2008). Statistics Canada. Recycling in Canada. Retrieved from http://www.statcan.gc.ca/pub/16-002-x/2007001/article/10174eng.htm 
Banks, Sam. (2008). Parliament of Canada. Jurisdiction Over Plastic Bag Regulation. Retrieved from http://www.parl.gc.ca/Content/LOP/ResearchPublications/prb0827e.htm\#introduction

Banks, Sam. (2008). Parliament of Canada. Plastic Bags: Reducing Their Use Through Regulation and Other Initiatives. Retrieved from http://www.parl.gc.ca/Content/LOP/ResearchPublications/prb0827e.htm\#introduction

Banks, Sam. (2008). Parliament of Canada. The Federal Government and Plastic Bag Regulation. Retrieved from http://www.parl.gc.ca/Content/LOP/ResearchPublications/prb0827e.htm\#introduction

Campbell, Don, and Thana Dharmarajah. (2011, October 19). Ontario Landfills are Filling Up Fast. The Record.com. Retrieved from http://www.therecord.com/newsstory/2589653-ontario-landfills-are-filling-up-fast/

Canadian Plastics Industry Association. (2013). Sustainability. Retrieved from http://www.plastics.ca./EnvironmentalSustainability/index.php

Clemente, Vanessa. (2008). Montrealities. Recycling Plastics Scandal. Retrieved from http://www.montrealites.ca/justice/recycling-plastics-scandals.html\#.UW6YKX3D-Y

Ecology Centre. (n.d.). Seven Misconceptions About Plastics and Plastic Recycling / Misconception \#5. Retrieved from http://www.ecologycenter.org/ptf/misconceptions.html

Edmonton.ca (2013) Recycling Facts / Recycling is Good for the Local Economy. [Pdf Brochure]. Edmonton, AB: Alberta. Retrieved from http://www.edmonton.ca/for_residents/PDF/City_recycle_factsheet(web).pdf

FuturEnergia. (n.d.) Biodegradable Plastics: Are They Better For The Environment? Retrieved from http://www.futurenergia.org/ww/en/pub/futurenergia/chats/bio_plastics.htm

Ian Connacher (Writer \& Director). (2008). Addicted to Plastic. [DVD]. Canada: Cryptic Moth Productions.

Landfill Inventory Management Ontario (LIMO). (2011). How You Can Search for Landfill Information. Retrieved from

http://www.ene.gov.on.ca/environment/en/monitoring_and_reporting/limo/inde 
x.htm

Moore, Capt. Charles, and Cassandra Phillips. (2011). Plastic Oceans. New York, NY: Penguin Group.

Plastics: How to Recycle Them and Where They Go. (2008, February 11). The Calgary Herald. Retrieved from http://www.canada.com/calgaryherald/news/reallife/greenguide/story.html?id=d7 b55eea-f6e3-

Plastic Pollution Coalition. (2012). The Ocean's Hot or Not List / So Not. [Pdf Brochure]. Retrieved from http://plasticpollutioncoalition.org/wpcontent/uploads/2010/04/HotOrNot.pdf4876-85d6-757fd4e8a5b4\&k=56556

Recycling Council of British Columbia. (n.d.) Where Does Our Garbage Go? / How Much Garbage?? [Pdf]. Retrieved from http://rcbc.bc.ca/files/u3/add_Think'TwiceBefore'ThrowingitAway_000.pdf

Recycling Council of Ontario. (2010). How Waste is Regulated. Retrieved from https://www.rco.on.ca/how_waste_is_regulated

Saskatchewan Waste Reduction Council. (2013, January). What Are Biodegradable Plastics?. Retrieved from http://www.saskwastereduction.ca/resources/plastics/biodegr.html

SPi The Plastic Industry Trade Association. (2012). FFBD Consumer Information / Better for Recycling. Retrieved from http://www.plasticsindustry.org/IndustryGroups/content.cfm?ItemNumber=520

SPi The Plastic Industry Trade Association. (2012). FFBD Consumer Information / Debunking Myths About Plastic Bags. Retrieved from http://www.plasticsindustry.org/IndustryGroups/content.cfm?ItemNumber=520

Toronto.ca (2013) Living in Toronto/Biodegradable Plastics Can Ruin Recycling Markets. Retrieved from http://www.toronto.ca/garbage/biodegradable_plastic.htm

Toronto.ca. (2013). Living in Toronto/Biodegradable Plastic Products and Bags Cause Problems for Municipal Recycling Systems." Retrieved from http://www.toronto.ca/garbage/biodegradable_plastic.htm 